ORIGINAL ARTICLE

\title{
Household and family characteristics of street children in Aracaju, Brazil
}

\author{
S Abdelgalil, R G Gurgel, S Theobald, L E Cuevas
}

Arch Dis Child 2004;89:817-820. doi: 10.1136/adc.2003.032078

See end of article for authors' affiliations

a............

Correspondence to: Dr L E Cuevas, Liverpool School of Tropical

Medicine, Pembroke Place, Liverpool' L3 5QA, UK; lcuevas@liv.ac.uk

Accepted 29 January 2004
Aims: To describe the family background of street children in Aracaju, Brazil, their parents' perception of street life, and the reasons for the high prevalence of males observed among street children.

Methods: Cross sectional study using semi-structured interviews and qualitative focus group discussions with parents of purposively selected index street children.

Results: Fifty eight families were enrolled. Most participants were single parent, female headed families living in slums or low cost housing, with high levels of illiteracy, drug use, unemployment, and a history of migration. Most parents reported receiving financial support from their children and were aware of the dangers of the street. Many parents had lived in the street, worked from an early age, and had been adolescent parents themselves. Parents perceived that the street was more dangerous for girls than for boys. Besides economic reasons, parents highlighted the role of peers and drug use in pulling their children to the street. A total of 187 siblings were identified. Siblings had poor school performance with high school drop out rates. Twenty per cent of the adolescent girl siblings were not living at home. Gender determined the type of work undertaken by children and adolescents. Males worked in the streets and females worked as housemaids, shop assistants, and in restaurants and bars.

Conclusion: Family disintegration, poverty, drug use, adolescent pregnancy, peer pressure, and socially constructed gender roles determine the characteristics of children in the street. There is an urgent need for increased social support in this area.
I: is estimated that there are 150 million street children worldwide. ${ }^{1}$ This phenomenon is often attributed to multiple factors including economic stagnation, unequal distribution of wealth, lack of welfare and social services, AIDS, and civil war. Children interviewed in the street often refer to their household's economic and family problems. There is however very limited literature that describes the views and characteristics of the families of these children. ${ }^{2-7}$ This is a missed opportunity in understanding the dynamic interplay of factors that push children towards street life, and has been recognised recently by some organisations that are trying to include families in the challenging process of rehabilitating street children. ${ }^{6}$

In addition, almost all reports indicate a clear gender imbalance in street children: $75-90 \%$ of Latin American and African street children are male. If girls are often half of the population, why is there such a gender difference? It has been suggested that boys become independent from an earlier age and that girls are taught to cope with poverty while staying at home. ${ }^{89}$

This study set out to describe the family and household characteristics of street children and explore the perceptions of parents that could explain these gender discrepancies.

\section{METHODS}

The study was conducted in Aracaju, Sergipe, in northeast Brazil. The north and the northeast of Brazil are less industrialised and poorer than the south of the country. Aracaju is a medium size city with a population of 675 667, of which 474055 are children $<20$ years old (47:53 male:female ratio). The city has high migration rates from rural areas, a rapid urbanisation process, and is representative of middle size cities in the northeast of the country. It is estimated that there are about 1500 street children in Aracaju.

The study took place in 2002, before the end of the presidential period of President Fernando E Cardoso, and aimed to describe the characteristics of the parents, their siblings, and the household of street children. The study was based on individual interviews of selected parents and siblings of street children and focus group discussions.

Index male street children who had at least one sibling were invited to participate. Street children were defined as children less than 18 years old not accompanied by an adult who were working or living in the street during most of the day. Children were contacted directly from street locations (markets, beaches, and tourist centres) or through Renascer and Casa de Passagem, which are organisations providing rehabilitation services for street children. Children with legal problems and/or under the protection of the courts were excluded. After explaining the aims of the study, children were asked for help to locate their families and were invited to witness the interview with their parents if they wished.

Semi-structured interviews with the parents were conducted by home visits and included the characteristics of the family, frequency of contact with the children, perception about the dangers of street life, the reasons why their children were in the street, and the location and activities of the siblings. Parents were invited to participate in qualitative focus group discussions (FGDs) at the end of the interview, to further explore interactively their perceptions of the factors pulling their children to the street and the observed gender difference in street children. An attempt was made to verify the residency of the female siblings absent from the household.

Informed consent procedures were followed with all study participants. The study protocol was approved by the Ethics Committee of the Liverpool School of Tropical Medicine (UK) and the Research Committee of the Federal University of Sergipe (Brazil).

The semi-structured interview responses were entered into EPI-INFO and analysed quantitatively. The FGDs were 
recorded, and analysed through a framework approach by identifying common themes. ${ }^{10}$

\section{RESULTS}

Fifty eight index street children, with a median age of 13 (range 6-16) years, were enrolled. Of these, 34 were contacted on the street and 24 through Renascer or Casa de Passagem. Most children said they were studying at the time of enrolment, but many could not read the consent form. Fifty one $(88 \%)$ had been in contact with the family during the week preceding the interview, but none of them were home based. The majority were middle siblings, with very few being the eldest or the youngest in the family. The factors most often mentioned of why they were in the street were poverty, domestic violence, drug abuse, and encouragement from peers.

\section{The household}

Families had a median of six family members and lived in slums or low cost housing in the outskirts of Aracaju. Although most houses had piped water and electricity, 26 $(41 \%)$ had no sanitary facilities. The majority were single parent families, of which 26 (46\%) were single female headed and four $(7 \%)$ single male headed households. Only 23 $(40 \%)$ biological fathers lived with the family. Two thirds of the parents had migrated to Aracaju and had high illiteracy levels, and only a few had completed elementary education. Most parents were unemployed and in one family none of the five adults was working. The few working mothers were housemaids, street sellers, ran small businesses, or were fisherwomen. Fathers also had low wage occupations as builders or fishermen. Their income was below the Brazilian minimum salary (MS) of R\$150/month with a mean of 0.5 MS and 0.7 MS for the mothers and fathers respectively. Mothers had started working since early adolescence; some were as young as 7 , and by the age of 14 nearly all had worked. The prevalence of adolescent pregnancy among the mothers was also high, and 54\% had had at least one child by 17 years of age. Tables 1 and 2 summarise the characteristics of street children's families and parents, respectively.

\section{The siblings}

The enumeration of all members of the household identified 187 siblings ( 86 male and 101 female). Their mean age was 9.9 years. One hundred and three $(73.6 \%)$ of the 143 children $<15$ years of age were attending school, compared to 29 $(65.9 \%)$ children above 15 years of age (see table 3$)$. In Brazil, children need to pass exams at the end of the school to

Table 1 Characteristics of the families of street children

\begin{tabular}{ll}
\hline & $\mathbf{n}=58$ \\
\hline Family size & $6[1-13]$ \\
No. of adults & $2[1-6]$ \\
No. children & $4[0-9]$ \\
Parents & $30(51.7)$ \\
$\quad$ Single (\%) & $26(45.6)$ \\
Female single (\%) & $4(6.9)$ \\
Male single (\%) & $11(19) ? ?$ \\
All employed (\%) & $37(64)$ \\
Only one parent & $10(17)$ \\
Both parents & $2[1-4]$ \\
Household & $53(91.4)$ \\
$\quad$ No. of rooms & $55(94.8)$ \\
Piped water (\%) & $32(55.2)$ \\
$\quad$ Electricity (\%) & \\
Sanitation (\%) & \\
\hline Results expressed as median and [range], unless specified.
\end{tabular}

Table 2 Characteristics of the parents

\begin{tabular}{|c|c|c|}
\hline Variable & $\begin{array}{l}\text { Mother } \\
\mathrm{n}=58\end{array}$ & $\begin{array}{l}\text { Father } \\
n=58\end{array}$ \\
\hline Age, mean (SD) & $\begin{array}{l}38(7) \\
{[26-56]}\end{array}$ & $\begin{array}{l}43(8) \\
{[26-59]}\end{array}$ \\
\hline \multicolumn{3}{|l|}{ Marital status } \\
\hline Single & $21(37)$ & NA \\
\hline Widow & $5(8)$ & NA \\
\hline Married & $23(40)$ & NA \\
\hline Remarried & $8(14)$ & NA \\
\hline \multicolumn{3}{|l|}{ Education (\%) } \\
\hline Illiterate & $20(36)$ & $10(25)$ \\
\hline Elementary & $33(580)$ & $25(63)$ \\
\hline Primary & $1(2)$ & $3(7)$ \\
\hline Secondary & $2(4)$ & $2(5)$ \\
\hline Unknown & - & 18 \\
\hline Working & $23(39 \%)$ & $25(43 \%)$ \\
\hline Income MS (SD) & $\begin{array}{l}0.5(0.5) \\
{[0-3]}\end{array}$ & $\begin{array}{l}0.7(0.73) \\
{[0-2]}\end{array}$ \\
\hline $\begin{array}{l}\text { Parent lives at home (\%) } \\
\text { Last contact with child }\end{array}$ & $54(62)$ & $23(40)$ \\
\hline Week & $43(75)$ & $16(73)$ \\
\hline Month & 10 (18) & $3(13)$ \\
\hline$>$ Month & $4(7)$ & $3(14)$ \\
\hline Unknown & 1 & 36 \\
\hline Immigrants & $36(62)$ & $32(65)$ \\
\hline Time since migration, mean (SD) & $\begin{array}{l}16(8) \\
{[4-31]}\end{array}$ & $\begin{array}{l}18(10) \\
{[4-46]}\end{array}$ \\
\hline Age started work, mean (SD) & $\begin{array}{l}13.8(5.2) \\
{[7-30]}\end{array}$ & NA \\
\hline Median age delivered first child & $\begin{array}{l}17 \\
{[12-34]}\end{array}$ & NA \\
\hline
\end{tabular}

Ranges in square parentheses.

progress to a higher level, and most siblings were below the expected grade for their age.

Thirty four (18\%) siblings, $22(25 \%)$ males and $12(12 \%)$ females, were working. Seventy per cent of the mothers regularly received money from their children and said that the extra income was needed to pay for food, clothes, and rent. Working male siblings were involved in street activities such as car washing, carrying goods, and shoe shining; female siblings worked as housemaids, baby sitters, or waitresses. The age of the female siblings was associated with the type of activity. Younger girls begged and sold small items in the street; older sisters were working in restaurants or bars, as housemaids, and three as sex workers. Some girls were under pressure to work as sex workers and follow their mothers' and aunts' activities and receive clients at home. Most girls did domestic work at home, but parents and children did not consider this as child labour. Thirty seven siblings were not living at home and girls were more often absent than boys (29\% versus $10 \%$ respectively). Parents said that girls were more often welcomed in their

Table 3 Characteristics of the siblings

\begin{tabular}{lll}
\hline Variable & $\begin{array}{l}\text { Male } \\
\mathbf{n}=86(\%)\end{array}$ & $\begin{array}{l}\text { Female } \\
\mathbf{n}=101\end{array}$ \\
\hline Mean age (SD) & $10(5)$ & $10(5)$ \\
Living at home (\%) & $78(90)$ & $72(71)$ \\
Studying (\%) & $65(77)$ & $67(68)$ \\
Underachievement in school & $38(44)$ & $32(32)$ \\
Education (\%) & $9(10)$ & $8(8)$ \\
Alfa & $53(62)$ & $48(47)$ \\
Elementary & $8(9)$ & $19(19)$ \\
Primary & 0 & $5(5)$ \\
Secondary & $16(19)$ & $21(21)$ \\
$\quad$ Unknown & $22(25)$ & $12(12)$ \\
Working (\%) & $7.2(2.2)$ & $8.1(2.1)$ \\
Working hours/day, mean (SD) & & \\
\hline
\end{tabular}


relatives' households when families disintegrated. The place of residency was also strongly associated with age, as eight of $16(50 \%)$ adolescent girls not living at home, were single mothers or lived with a boyfriend or husband. We were unable to locate all the sisters, as some were in the street, involved in drug use, or working as sex workers. Male siblings not living at home were either living in non-governmental organisations (NGOs) or on the street.

\section{Families' perceptions of factors pushing children to life on the street}

Together with the high rate of family disintegration, children and parents reported physical abuse as a major factor pushing children away from home. Parental illness (physical and mental), and drug and alcohol use among the fathers and stepfathers were considered precipitating factors for family disruption. Children frequently used drugs, and said that drugs were easily obtained within the neighbourhood and that parents often pushed their addicted children away from the home.

Most parents reported that street life was dangerous with a high risk of death. Some parents had been street children themselves and were aware of the dangers, often worrying about drugs, accidents, and murder. Parental fears for girls were mainly fear of rape and sexual harassment. None of the parents perceived the negative influence that street life could have on their children's psychological development, recreation, education, or school performance.

The focus groups further identified perceptions that could explain the gender differences in numbers of street children. Parents often perceived that "girls should be brought up at home while boys [could go] free, [and were] strong and could do anything" ( 33 year old mother). A minority thought that gender roles were irrelevant and that boys and girls both had to work and live in the street as a survival strategy. Boys were encouraged to become independent and to survive in the street at an early age: "boys suffer more than girls, as when they are 13 years old they must work, otherwise they won't eat at home" (15 year old boy). Girls were expected to help their families in a different way, often through domestic work: "girls are busy working at home, they do not have time to think about other things, but boys feel that the house is like a jail so they go to the street to play with their friends" (14 year old girl). Parents were often more "careful" with girls because "boys have more courage and know how to protect themselves". The influence of peers and friends was frequently mentioned as a precipitating factor and a key factor to initiation of drug and alcohol use.

\section{DISCUSSION}

The index children enrolled in the study had the characteristics of most street children in Brazil; the majority were boys, with a median of 13 years of age, and maintained sporadic contact with the family. ${ }^{1-3}{ }^{11}{ }^{12}$ These children reported a high rate of domestic violence, mainly physical abuse.

Nearly all parents had low education and qualifications and high unemployment rates, which was strongly associated with the children being asked to work to contribute to the family income. Income in Brazil is often quantified and the minimum salary and household income is measured in multiples of MS. The MS is set by the government and defines the poverty line; most of the families were below this level.

Poverty however was not the sole contributory factor, as other families in the neighbourhood managed to retain their children at home. Similar findings were reported from Rio de Janeiro, ${ }^{3}$ and other authors have reported an association between street children, the family structure, and parenting style, and a weak association between leaving home, poverty, and economic crisis. ${ }^{413-15}$ The higher number of female headed households reflects the traditional gender role of the mother maintaining responsibility for the child/children after separation of the couple. Many mothers had new unstable relationships and had themselves experienced adolescent pregnancies. In addition, most parents had started work at an early age and their teenage daughters had often left home and had become adolescent mothers themselves, perpetuating a vicious cycle of low education, low income, and unstable relationships.

Half of the street children of Aracaju have experienced or used drugs, ${ }^{16}$ and there have been reports of an increased use of crack, cocaine, and marijuana among Brazilian street children. ${ }^{1}$ Drug use is often associated with family disruption $^{17}$ and the index children and their parents identified in this study often used drug and alcohol. Drug use constituted one of the main worries of the parents about street life. Parents and siblings agreed that drug abuse was more common among boys than girls as they have more freedom of movement and are more susceptible to the influence of peers. Drug use is a recognised trigger for family disintegration and for leaving home in large cities such as Rio de Janeiro and Sao Paulo; ${ }^{37}$ the present study suggests this is also a key factor in smaller cities such as Aracaju.

Gender roles, relations, and expectations clearly impact on the experiences and activities of children on and off the street.9 ${ }^{18} 19$ Families perceived that the street was more dangerous for the girls. The parents' lack of employment was strongly associated with the children working during the day, but not necessarily with whether children still lived at home at night or had left permanently. Childcare and household chores were considered natural duties for girls and as an indirect way to support the family. Boys were expected to adapt to the outdoor/street environment from an early age as a necessary pathway to supplement the family's income, despite most parents being aware of the associated increased exposure to violence, drugs, and accidents. This is often described as a coping strategy for poverty as parents teach their sons to become independent. These gender differences in roles and child rearing strategies help to explain the higher prevalence of boys living on the street.

Thus the ways in which gender roles are constructed and experienced can be potentially harmful to both male and female children. In this context boys are frequently expected to work to survive and be independent in early life, as well as appearing to be more vulnerable to peer pressure. This can result in boys ending up in the harsh environment of the street. Societal and parental expectations mean than girls are more likely to remain at home doing housework and child rearing. Girls living in the street have often experienced serious family problems, with more frequent histories of sexual and physical abuse before leaving the household. Drug addiction, prostitution, and the street is the last resort for these girls. ${ }^{820}$

Very few studies have systematically addressed the effect of the peers' influence as a pulling factor to street life. Parents, siblings, and index children in Aracaju frequently mentioned the influence of male friends as a decisive step to leave home or get involved in drugs and alcohol. Matchinda (1999) found a strong association between having friendships with children living in the street and making the decision to leave. ${ }^{4}$ Children with a poor family environment may be more susceptible to this influence, refocusing trust and confidence to their peers as a way to fill the void left by the family. Finally, it is important to highlight that parents did not mention the rights of the children to recreation, psychological development, or education. 
Parents' perceptions of the rights of their children need to be further explored.

\section{Conclusion}

Family disintegration, poverty, drug use, adolescent pregnancy, peer pressure, and socially constructed gender roles thus seem to play important and dynamic roles in shaping the characteristics of street children. These factors are interrelated, affecting children's experiences of family life and their social, economic, and psychological coping strategies, both on the street and at home. This study used mixed methods-the cross sectional survey enabled a quantification of the main characteristics of street children's families. The qualitative FGDs opened up spaces for street children's families to articulate their experiences and concerns about life on the street and how this is shaped by gender roles. These research approaches both confirm an urgent need for increased social support in this area. ${ }^{12}$ Most families maintain fairly regular contact with their children who are living on the street. Gender sensitive strategies that focus on creative ways to strengthen street children's links with their families may yield positive results. Working with parents to explore the effect of domestic labour, street life, and drugs on the wellbeing of their boys and girls may offer opportunities to modify the expectation that children from disadvantaged situations should work from an early age.

\section{Authors' affiliations}

S Abdelgalil, Department of Paediatrics and Child Health, University of Khartoum, Sudan

R G Gurgel, Federal University of Sergipe Aracaju, Sergipe, Brazil S Theobald, L E Cuevas, Liverpool School of Tropical Medicine, Liverpool, UK

\section{REFERENCES}

1 Scanlon TJ, Tomkins A, Lynch MA, et al. Street children in Latin America. BMJ 1998;316:1596-600.

2 Aneci Rosa CS, Borba ES, Ebrahim GJ. The street children of Recife: a study of their background. J Trop Pediatr 1992;38:34-40.

3 Martins SB, Ebrahim GJ. Street children. J Trop Pediatr 1993:39:264-8.

4 Matchinda $\mathbf{B}$. The impact of home background on the decision of children to run away: the case of Yaounde City street children in Cameroon. Child Abuse Negl 1999;23:245-55.

5 Whitbeck LB, Hoyt DR, Ackley KA. Families of homeless and runaway adolescents: a comparison of parent/caretaker and adolescent perspectives on parenting, family violence, and adolescent conduct. Child Abuse Negl 1997;21:517-28.

6 Le Roux J. Street children in South Africa: findings from interviews on the background of street children in Pretoria, South Africa. Adolescence 1996;31:423-31.

7 D'Abreu RC, Mullis AK, Cook LR. The resiliency of street children in Brazil. Adolescence 1999;34:745-51.

8 Raffaelli M, Koller SH, Reppold CT, et al. Gender differences in Brazilian street youth's family circumstances and experiences on the street. Child Abuse Negl 2000;24: 1431-41.

9 Aptekar L, Ciano-Federoff LM. Street children in Nairobi: gender differences in mental health. New Dir Child Adolesc Dev 1999;(85):35-46.

10 Ritchie J, Spencer L. Qualitative data analysis for applied policy research. London: Routledge, 1994.

11 le Roux J, Smith CS. Causes and characteristics of the street child phenomenon: a global perspective. Adolescence 1998;33:683-8.

12 Ennew J. A guide for planning and methods of research with street children and working children. Save the Children, 1997.

13 Navartis. Street children in Brazil: Navartis Foundation for Sustainable Development, 2001

14 le Roux J. The worldwide phenomenon of street children: conceptual analysis. Adolescence 1996;31:965-71.

15 Lalor KJ. Street children: a comparative perspective. Child Abuse Negl 1999:23:759-70.

16 Shinkafi Z. Street children in Aracaju: a situation analysis. Masters in Tropical Paediatrics. Liverpool School of Tropical Medicine, 1999.

17 Inciardi JA, Surratt HL. Children in the streets of Brazil: drug use, crime, violence, and HIV risks. Subst Use Misuse 1998:33:1461-80.

18 Barrett D, Beckett W. Child prostitution: reaching out to children who sell sex to survive. Br J Nurs 1996;5:1120-5.

19 Harris B. Suffer the little children. Lancet 2000;355:1805.

20 Martins SB, Ebrahim GJ. The female street children of Rio de Janeiro: a qualitative study of their backgrounds. J Trop Pediatr 1995;41:43-6.

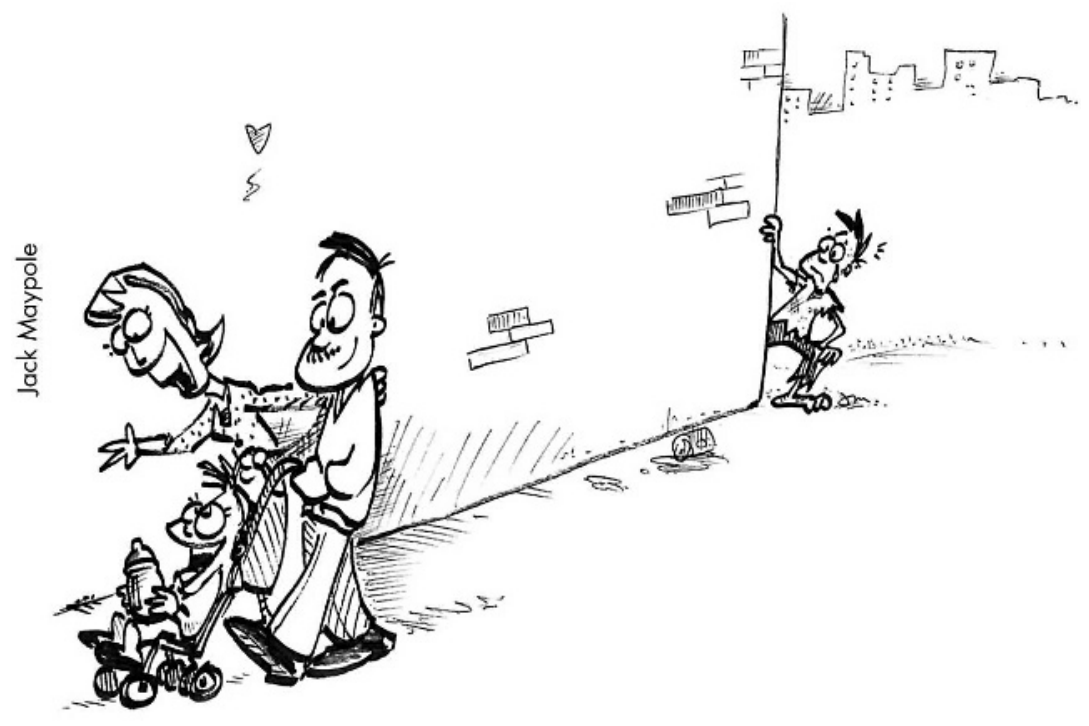

